\title{
A study on isolation and identification of bacterial agents responsible for postoperative wound infection
}

\author{
Sarma MC', Das $\mathrm{DK}^{2}$ \\ Received on December 22, 2016; editorial approval on December 5, 2018
}

\begin{abstract}
Introduction: The term post operative wound infection, also known by the term surgical site infection (SSI) is as old as the beginning of surgery. The majority of post operative wound infection (SSI) become apparent within 30 days of an operative procedure and most often between $5^{\text {th }}$ and $10^{\text {th }}$ post operative days. Materials and methods: This was a hospital based observational, descriptive study carried out on 2685 SSI wound samples were included in the present study collected from General Surgery, Orthopedic, Obstetrics and Gynaecology Departments. Results: In the present study in the clean wound category with no obvious source of contamination, $65.8 \%$ of the cultured infected wounds were of monomicrobial etiology. The isolates when compared with the duration of surgery, it was found that with longer durations of surgery, the wound was infected with polymicrobial agents, The incidence of Klebsiella, E.coli and Pseudomonas increased with longer durations of surgery. This suggests that the organisms might be transferred to the wound by prolonged contact with the operating staff and equipment, as airborne spread of the Gram negative organisms is rare. Conclusion: The present study has enlightened the relationship between SSI, preoperative hospitalization and duration of surgery. There was increase in the incidence of infection, in patients with longer preoperative hospitalization and longer durations of surgery. There was an increase in poly-microbial etiological agents in these cases. Klebsiella was found to be the main etiological agent followed by E. coli, Pseudomonas, Coagulase negative staphylococci, etc.
\end{abstract}

Keyword: Surgical site infection (SSI); polymicrobial agents; cultures positive; cultures negative; coagulase positive; coagulase negative.

\section{INTRODUCTION}

The term post operative wound infection, also now by the term surgical site infection (SSI) ${ }^{1}$ is as old as the beginning of surgery. Survey on post operative wound infection (SSI) by different workers show that the incidence is still alarming which frightens both surgeons and patient. ${ }^{2,3}$

The majority of post operative wound infection (SSI) become apparent within 30 days of an operative procedure and most often between $5^{\text {th }}$ and $10^{\text {th }}$ post operative days. However, where a prosthetic implant is used, infection affecting the deeper tissues may occur several month after the operation. ${ }^{4,5,6}$ Altimeter stated that the principal organisms of SSI were staphylococcus (both coagulase positive and negative) Escherichia coli, proteous, klebsiella, pseudomonas, bacteroides, streptococcus and Clostridium perfringens. Since last 25 year, ${ }^{7,89}$ the incidence of wound infection due to gram negative organisms is increasing though, staphylococcal infection was more common earlier. ${ }^{10}$

The C.D.C. definition describes three level of post operative wound infection (SSI)

a) Superficial incisional, affecting the skin and subcutaneous tissue.

b) Deep incisional affecting the facial or muscle layers.

c) Organ or space infection, which involves any part of the anatomy other than the incision that is opened or manipulated during the surgical procedure, for example joint or peritoneum. This paper has aimed to isolate and identify the bacterial agents

\author{
Address for correspondence: \\ ${ }^{1}$ Assistant Professor \\ Dept. of Microbiology \\ FAAMC, Barpeta \\ Mobile: +919864043467 \\ ${ }^{2}$ Associate Professor (Corresponding Author) \\ Dept. of Microbiology \\ Gauhati Medical College, Guwahati \\ Email: drdipakdad606@gmail.com \\ Mobile: +919435474891
}

Cite this article as: Sarma MC, Das DK. TA study on isolation and identification of bacterial agents responsible for postoperative wound infection. Int J Health Res Medico Leg Prae 2019 July;5(2):18-22. DOI 10.31741/ijhrmlp.v5.i2.2019.4 
responsible for postoperative wound infection (SSI).

\section{MATERIALS AND METHODS}

A total of 2685 S.S.I. wound sample were included in the present study. It was carried out in the Department of, Microbiology, Gauhati Medical College and Hospital for a period of one year. The materials were obtained from patients in the General Surgery, Obstetrics \& Gynaecology and Orthopaedic Departments of GMCH, who had undergone operations and had developed Signs and Symptoms of postoperative wound infections. Cases of Clean and Clean contaminated surgeries are included for the study, whereas procedures in which healthy skin was not incised such as opening of an abscess, burn injuries and donor sites of split skin grafts, contaminated and dirty surgeries are excluded from study samples.

\section{Collection and transportation of material}

The wounds were examined for suggestive Signs/Symptoms of infection in the post operative period, during wound dressing or when the dressings were soaked, until the patient was discharged from the hospital and also in the Out-patient department after discharge. All the specimens collected were transported immediately to the laboratory for further processing. The Nutrient broth and Robertson's cooked meat broth $(\mathrm{RCMB})$ were incubated at $37^{\circ} \mathrm{C}$.

Methods: The samples collected were processed as follows

a) Direct microscopic examination of gram stained smear. The smear was screened for pus cells, the gram reaction, morphology, arrangement and number of types of the organisms were noted.

b) Inoculation of the samples onto different culture media for aerobic and anaerobic onto plates of MacConkey agar and 5\% Sheep blood agar.

c) Preliminary identification.

d) Bio-chemical tests.

\section{RESULTS}

The following results were made from the study.

Table 1 Age and sex distribution of cases

\begin{tabular}{|l|l|l|l|}
\hline $\begin{array}{l}\text { Age Group } \\
\text { (in Years) }\end{array}$ & $\begin{array}{l}\text { Total No. of Cases } \\
\text { Surgeries } \\
\text { Performed }\end{array}$ & Male & Female \\
\hline $\mathbf{0 - 1 0}$ & 28 & 21 & 7 \\
\hline $\mathbf{1 1 - 2 0}$ & 175 & 134 & 41 \\
\hline $\mathbf{2 1 - 3 0}$ & 526 & 439 & 87 \\
\hline $\mathbf{3 1 - 4 0}$ & 752 & 588 & 164 \\
\hline $\mathbf{4 1 - 5 0}$ & 711 & 622 & 89 \\
\hline $\mathbf{5 1 - 6 0}$ & 348 & 246 & 102 \\
\hline Above 60 & 93 & 74 & 19 \\
\hline Total & $\mathbf{2 6 8 5}$ & $\mathbf{2 1 2 4}$ & $\mathbf{5 6 1}$ \\
\hline
\end{tabular}

Table 1 Shows that maximum number of samples $752(28 \%)$ were $31-40$ years, followed by $711(26.5 \%)-50$ years and $93(3.5 \%)$ samples were above the age of 70 years. Male and female ratio found to be $4: 1$.

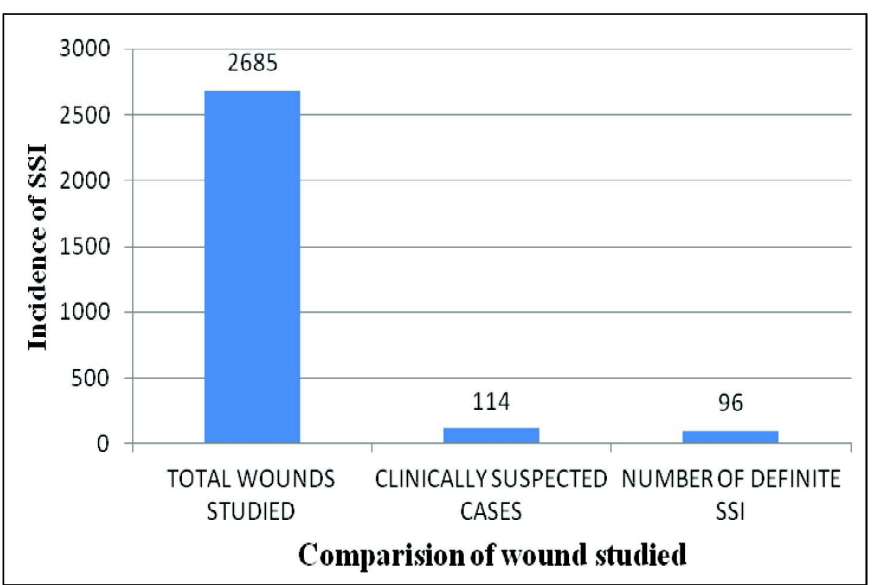

Figure 1 Incidence of SSI

Figure 1 depicts out of the 2685 cases with surgical wounds, 114 cases $(4.2 \%)$ were suspected to be clinically infected. Amongst 114(4.2\%) infected wounds, 96(3.6\%) were found culture positive and were considered definite cases of surgical site infection.

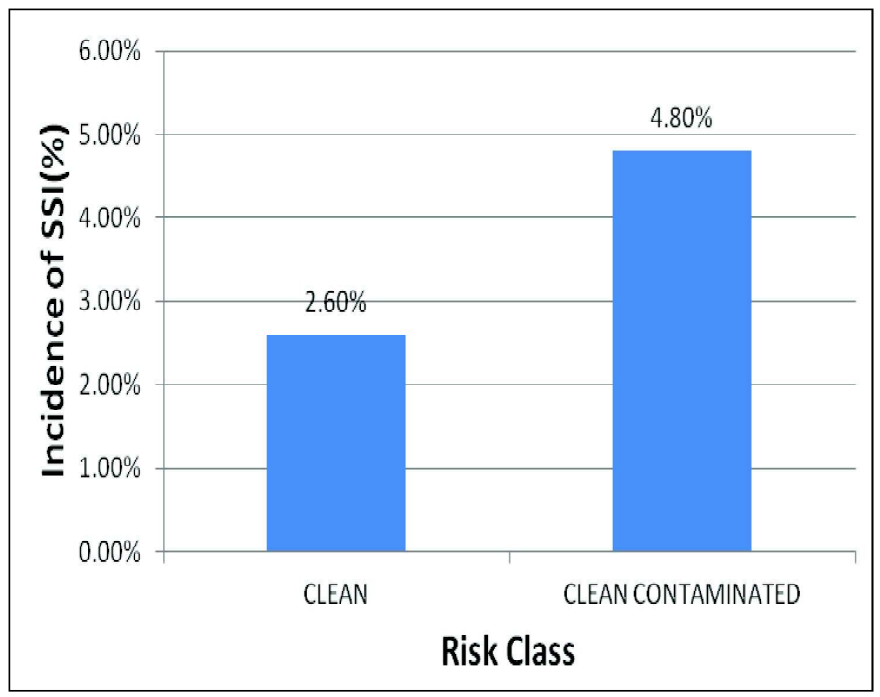

Figure 2 Comparison of incidence of SSI according to risk class

Figure 2 depicts out of the 1471 operations included in the clean wound category, 38 cases $(2.6 \%)$ were infected. The incidence of wound infection was significantly high in the clean contaminated wounds, with 58 cases $(4.8 \%)$ being infected in 1214 surgeries.

Table 2 shows, out of the 50 wounds clinically suspected to be infected and studied in the clean wound category, $38(76 \%)$ were culture positive. In the 64 clinically infected cases of the clean contaminated category, 58 
cases $(90.6 \%)$ were culture positive for various organisms. 18 samples $(15.8 \%)$ of the 114 samples studied were cultures negative. Organisms in all the positive cultures were identified as strict aerobe and facultative anaerobe where as none could be identified as strict anaerobe.

Table 2 Aerobic culture positivity in the wound studied

\begin{tabular}{|l|l|l|l|l|c|c|c|}
\hline \multicolumn{2}{|l|}{ Risk class } & \multicolumn{2}{l|}{ Clinically Infected } & \multicolumn{2}{c|}{ Culture Positive } & \multicolumn{2}{c|}{ Culture Negative } \\
\hline & No. & No. & $\%$ & No. & $\%$ & No. & 12 \\
\hline Clean & 1471 & 50 & 3.4 & 38 & 76 & 6.4 \\
\hline $\begin{array}{l}\text { Clean } \\
\text { Contaminated }\end{array}$ & 1211 & 64 & 5.3 & 58 & 90.6 & & \\
\hline Total & $\mathbf{2 6 8 5}$ & $\mathbf{1 1 4}$ & $\mathbf{4 . 2}$ & $\mathbf{9 6}$ & $\mathbf{8 4 . 2}$ & $\mathbf{1 8}$ & $\mathbf{1 5 . 8}$ \\
\hline
\end{tabular}

Table 3 Comparison of wounds and culture positive cases with pre-operative hospitalization

\begin{tabular}{|l|ll|ll|}
\hline $\begin{array}{l}\text { Pre-operative } \\
\text { Hospitalization }\end{array}$ & \multicolumn{2}{|l|}{$\begin{array}{l}\text { Surgeries } \\
\text { Performed }\end{array}$} & No & \multicolumn{2}{|l|}{$\begin{array}{l}\text { Culture } \\
\text { Positive cases }\end{array}$} \\
\hline & 1546 & 57.7 & 21 & 1.3 \\
\hline Upto 1 day & 683 & 25.4 & 43 & 6.2 \\
\hline 2 days to 1 week & 16.9 & 32 & 7.01 \\
\hline More than 1 week & 456 & 16 & $\%$ \\
\hline
\end{tabular}

The above table (Table 3) shows, there is an appreciable increase of surgical site infection in patients with a longer pre-operative hospital stay. Among the 1546 patients (57.71\%) who had a preoperative hospitalization of upto 1 day and the infection rate was $1.3 \%$. The rate of infection showed an increase to $6.2 \%$ in the 683 patients $(25.4 \%)$ hospitalized 2 to 7 days before surgery. The rate further increased to $7.01 \%$ in the $456(16.9 \%)$ patients admitted for more than 7 days prior to surgery.

Table 4 Comparison of wound and culture positive cases with duration of surgery

\begin{tabular}{|l|ll|ll|}
\hline $\begin{array}{l}\text { Duration of surgery } \\
\text { (minutes) }\end{array}$ & \multicolumn{2}{|l|}{$\begin{array}{l}\text { Surgeries } \\
\text { Performed }\end{array}$} & \multicolumn{2}{|l|}{$\begin{array}{l}\text { Culture Positive } \\
\text { cases }\end{array}$} \\
\hline & No & $\%$ & No & $\%$ \\
\hline $0-60$ & 1865 & 69.5 & 46 & 2.5 \\
\hline $61-120$ & 691 & 25.7 & 33 & 4.8 \\
\hline Above 121 & 130 & 4.8 & 17 & 13.07 \\
\hline
\end{tabular}

The above table (Table 4) shows, the duration of surgery in majority of the cases was less than 1 hour. The infection rate showed a marked increase with longer duration of surgery. In 1865 cases which took less than 1 hour, 46 cases $(2.5 \%)$ were infected. In 691 cases which took 1 hour to 2 hour, 33 cases (4.8\%) were infected. Among the 30 cases which took more than 2 hours 17 cases $(13.07 \%)$ were infected.
Table 5 Organisms isolated in 96 SSI

\begin{tabular}{|l|l|l|}
\hline Organism & No. & \% \\
\hline Klebsiella species & 35 & 22.3 \\
\hline Staphylococcus aureus & 31 & 19.4 \\
\hline E.coli & 24 & 15.3 \\
\hline Pseudomonas & 20 & 12.7 \\
\hline Cons & 18 & 11.5 \\
\hline Acinetobacter & 07 & 4.5 \\
\hline Proteus species & 07 & 45 \\
\hline Diptheroids & 05 & 3.2 \\
\hline Citrobacter & 03 & 1.9 \\
\hline Enterococci & 02 & 1.3 \\
\hline S.pyogenes & 02 & 1.3 \\
\hline Candida & 03 & 1.9 \\
\hline Total & $\mathbf{1 5 7}$ & - \\
\hline
\end{tabular}

\section{DISCUSSION}

One of the most known important factors influencing the incidence of post operative wound infections is wound contamination class. Among the Clean wounds, which accounted for more than half the number of cases, the rate of infection was only $2.6 \%$. But in Clean contaminated cases, the rate of infection almost doubled to $4.8 \%$. probably because of profound influence of endogenous contamination.

The present study confirms the understanding that there is a gradual rise in incidence of wound infection as age advances. The incidence showed a gradual rise from $2.5 \%$ in the $21-30$ age group to $8.6 \%$ in patients more than 60 years. The finding is similar with study carried out by Cruse and Foord., ${ }^{411}$

The surgical patient is colonized by microorganisms, during his stay in the hospital. Longer preoperative hospitalization is associated with wound infection. In present study, the incidence 
was $1.3 \%$ in the patients hospitalized up to 1 day, $6.2 \%$ in patients hospitalized for 2 days to 1 week and $7.01 \%$ in patients hospitalized for more than a week. It was consistent with study of Anvikar. ${ }^{12}$

In the present study, majority of the surgical procedures lasted for less than 1 hour and the infection rate among these cases was $2.5 \%$. The rate roughly doubled to $4.8 \%$ when the duration of the procedure was 1 hour to 2 hours, and trebled to $13.07 \%$, in procedures lasting for more than 2 hours. This finding is in consistent with study carried out by Cruse and Foord. ${ }^{11}$

The increased incidence of infection may be due to contamination of the wound, by bacteria sedimented from exogenous sources over the duration of time. The length of incision is usually less, in surgeries which take a shorter duration, than in longer surgeries where the area exposed to the environment is more due to longer incisions and also a larger degree of damage to tissues and local disruption. In the present study, on direct microscopy $84.2 \%$ samples yielded growth on culture and this finding was in consistent with study of Anvikar et al. ${ }^{12}$

There is a change in the bacterial etiology of surgical infections from time to time. A century ago, the most feared and frequent pathogen was Streptococcus, twenty years ago the Coagulase positive staphylococcus was the principal offender, Gram negative bacilli are now replacing staphylococcus. . $^{3,13,14}$

The present study shows the emergence of Gram negative bacilli accounting for $61 \%$ of the isolates, as the principal offenders of surgical wound infection. In the present study anaerobic organisms were not isolated on culture, probably because the patients were treated with prophylactic and therapeutic antibiotics against anaerobes.

In the present study of 114 clinically suspected SSI, 96 yielded aerobic bacterial growth accounting for a total of 157 organisms. Mono-microbial isolates were encountered in $52(54.4 \%)$ of the wounds, 44 wounds $(45.8 \%)$ yielded polymicrobial agents, Gram positive and Gram negative organisms were frequently involved in the mixed infections. Staphylococcus aureus and E.Coli were the commonest combination present in 7 cases $(15.9 \%)$. Similar spectrum of organisms was observed by Giacometti, et al, who isolated 1060 bacterial strains from 614 individuals. ${ }^{11}$

The clean wound category with no obvious source of contamination, $65.8 \%$ of the cultured infected wounds were of monomicrobial etiology. The isolates when compared with the duration of surgery, it was found that with longer durations of surgery, the wound was infected with polymicrobial agents, The incidence of Klebsiella, E.coli and Pseudomonas increased with longer durations of surgery. This suggests that the organisms might be transferred to the wound by prolonged contact with the operating staff and equipment, as airborne spread of the Gram negative organisms is rare. ${ }^{15,16}$

\section{CONCLUSION}

The present that was conducted in Gauhati Medical College Hospital, Guwahati has enlighten the relationship between SSI, preoperative hospitalization and duration of surgery. There was increase in the incidence of infection, in patients with longer preoperative hospitalization and longer durations of surgery. There was an increase in poly-microbial etiological agents in these cases. Klebsiella was found to be the main etiological agent followed by E Coli, Pseudomonas, Coagulase negative staphylococci etc. It was observed that the gram negative bacilli were the main offenders in Clean contaminated operations, in patients with longer preoperative hospitalization and in surgeries with increased duration. Based on the above observations preventive and prophylactic measures can be enhance to lower down the incidence of post operative wound infection (SSI)

Conflict of interest: None declared.

Ethical clearance: Taken.

Source of funding: None declared.

Author Disclosure: (1) The article is original with the author(s) and does not infringe any copyright or violate any other right of any third party. (2) The article has not been published (whole or in part) elsewhere, and is not being considered for publication elsewhere in any form, except as provided herein. (3) All author(s) have contributed sufficiently in the article to take public responsibility for it and (4) all author(s) have reviewed the final version of the above manuscript and approved it for publication.

\section{REFERENCES}

1. Horan TC, Gaynes RP, Martone WJ, Garvis WR \& Emori TG. TDC definition of nosocomial surgical site infection : A modification of CDC definition of surgical wound infection. Infect control Hosp. Epidemiol 1992;13:606-8.

2. Geffrey JS \& Sklaroff SA. Incidence of wound infection. Lancet 1958;1:365-8.

3. Barber M. Hospital infection yesterday and today. J clin path 1961;14:2-10.

4. Bernard HR \& Cote WR. The prophylaxis of surgical infection; the effect of prophylactic antimicrobial dregs on the incidence of infection following potentially contaminated operation. Surg. 1964;56:151-5.

5. Ryan E.A. Wound infection by topical antibiotic. Brit G Surg 1967;54(5):324-9.

6. Wright JE, Hennessy EJ \& Bissest RL. Wound infection; Experience with 12000 sutured surgical wounds in a general hospital over a period of 11 years. Austr and NZJ Surg 1971;41(7):107-12.

7. Sturat M. Gram negative bacteraemia in colonic and rectal surgery. Med J Aust 1972;1(10):493.

8. Karstein M, Flower M, Massinger HL \& Gross PA. Surveillance for the post operative wound infection: Practical aspect. Am Surg 1978;44(4):210-14. 
9. Kapur BML, Shriniwas, Gupta A. Role of intra operative contamination in post operative wound infection in laparotomy. India J Red Res 1985;81:508-13.

10. Altemeier AW. Surgical infection Incisional wounds in hospital infection. Boston. John V. Bennett and Company; 1979;287-306.

11. Cruse PJ, Foord R. The epidemiology of wound infection. A ten year prospective study of 62, 939 wound. Surg Clin North Am 1980;60:27-40.

12. Anvikar AR, Deshmukh AB. A one year prospective study of 3280 surgical wounds. IJMM $1999 ; 17(3): 129-32$.
13. Howard JR. Surgical infections principles of surgery. Schwartz. New Delhi: Mc Graw hills; 2010. vo1 p. 143-75.

14. Eickhoff CT, John.RB, Philip SB. Antibiotics \& Nosocomial infections, Hospital infections, $4^{\text {th }}$ ed. Philadelphia and Toronto: Lippincott-Raven publishers; 1998;201-14.

15. Ayliffe A, AJied G, Fraise AP. Control of hospital infection. Arnold. $4^{\text {th }}$ ed. New York: Varghese Publishing House; 2006. p. 1157-60.

16. Hunt KT, Reid VM. Inflammation, Infection \& antibiotics. Medical Management of the surgical patient. $3^{\text {rd }}$ ed. Philadelphia and Toronto: JB Lippincott company; 2010. p. 356-58. 
